\section{Cureus}

Received 05/13/2017

Review began 05/24/2017

Review ended 05/26/2017

Published 06/03/2017

\section{(c) Copyright 2017}

Anjum et al. This is an open access article distributed under the terms of the Creative Commons Attribution License CC-BY 3.0., which permits unrestricted use, distribution, and reproduction in any medium, provided the original author and source are credited.

\title{
Transradial vs. Transfemoral Approach in Cardiac Catheterization: A Literature Review
}

Ibrar Anjum ${ }^{1}$, Muhammad Adnan Khan ${ }^{2}$, Muhammad Aadil ${ }^{3}$, Aniqa Faraz ${ }^{4}$, Mudassir Farooqui ${ }^{5}$, Amerah Hashmi ${ }^{6}$

1. Internal Medicine, The University of Texas MD Anderson Cancer Center, Houston, USA 2. Neurosciences \& Neurology, California Institute of Neurosciences, Thousand Oaks, USA 3. Department of Medicine, FMH College of Medicine and Dentistry, NEWARK, USA 4. Internal Medicine, Jacobs School of Medicine and Biomedical Sciences, University at Buffalo, State University of New York, Buffalo, New York, Buffalo, USA 5. Public Health, University of Oklahoma 6. Neurosciences \& Psychology, California Institute of Behavioral Neurosciences \& Psychology

$\square$ Corresponding author: Ibrar Anjum, ibrar.anjum@gmail.com Disclosures can be found in Additional Information at the end of the article

\section{Abstract}

The main objective of this review paper is to study the comparison between transradial and transfemoral approach in catheterization. Transradial and transfemoral are two main approaches which are used as a diagnostic and therapeutic purpose in catheterization. The transradial approach in interventional cardiology is safe, effective, and feasible as compared to the transfemoral approach. The aim of this study is to compare pros and cons of transradial vs. transfemoral approach in catheterization.

We conducted this systematic review on the role of transradial vs. transfemoral catheterization. The articles included real human data on interventional approaches. Reviews on these strategies were conducted in PubMed, medical literature analysis and retrieval system online (MEDLINE), Cochrane, Medscape and National Institute of Health. To maintain a high standard of review, studies published in all non-famous journals were excluded.

Data collected from the studies have suggested that transradial approach has less bleeding complications, cost effective, decreased hospital mortality rate, and less access site complications as compared to transfemoral approach. However, longer procedural duration and radiation exposure are still concerns regarding transradial approach.

The findings of the present study show that transradial approach in catheterization is safe, effective, and feasible as compared to the transfemoral approach. However, duration and radiation exposure are higher in the transradial access. Several studies suggest that the modern approach overweight in benefits with the comparison to the classical approach.

Categories: Cardiac/Thoracic/Vascular Surgery, Internal Medicine, Quality Improvement Keywords: transradial vs. transfemoral approach in catheterization, radial vs. femoral access, percutaneous coronary intervention, transradial and transfemoral approach, catheterization, transradial in coronary heart disease

\section{Introduction And Background}

The interventional cardiology deals with the catheter-based treatment of structural heart 
diseases. It uses diagnosing and treating the cardiovascular diseases, including congenital and structural heart diseases through catheter-based procedures such as angioplasty and stenting. Andreas Gruentzig is considered as the father of interventional cardiology [1]. He was the first who performed successfully coronary angioplasty on an awake human in September 1977. He opened occluded left anterior descending (LAD) which is a branch of left coronary artery usually involved in most myocardial infarction patients. Until the 1950s, Sones techniques introduced by Dr. Mason Sone which is popular to cut down soft tissue to visualized artery or vein to pass the catheter was used. The percutaneous approach that is widely used today was developed by radiologist Sven-Ivar Seldinger [2]. Percutaneous coronary intervention (PCI) also known as angioplasty is used to open blocked coronary vessels in the heart. It improves blood flow and decreases the mortality in acute coronary syndrome patients. Mostly the procedures are performed in cardiology via catheterization by either femoral or radial access.

The main advantages of using catheterization approach are a rapid recovery with early ambulation, less postoperative complications, less hospital cost and less chance of scars formation. Thus, it increases the patient comfort [3]. Additionally, angioplasty is now considered as a gold standard procedure for the treatment of acute myocardial infarction. The purpose of writing this paper is to investigate the pros and cons of transradial vs. transfemoral approach catheterization.

Transfemoral is considered as a classical approach over transradial due to the unlimited repetition of puncturing, easy access, less radiation time, and less contrast. In the last two decades, transradial approach emerged as mostly being used for the interventional and diagnostic approach in cardiology. In 1989 the transradial approach coronary angiography was reported for the first time in Campeau [4]. The reason behind the popularity of transradial approach is reduced bleeding risk, reduced hematoma formation, early discharge, it is patient preferred, low cost, and lower risk of morbidity and mortality [3, 5-7]. Many trials have proved that transradial approach has the lower risk of bleeding in ST-Segment elevation myocardial infarction (STEMI) patients using anticoagulation as compared to transfemoral approach [8-10]. The transition from femoral access to a radial access is safe and efficient in many procedures in interventional cardiology. It has fewer side effects of low bleeding, pseudoaneurysm, low cost, morbidity and mortality [11- 12]. The outcome of the transradial is much better as compared to the transfemoral approach in catheterization $[1-4,6]$.

\section{Review}

\section{Method}

We conducted this systematic review on the role of transradial versus transfemoral in catheterization. Reviews on these approaches were conducted in PubMed, MEDLINE, Cochrane, Medscape and National Institute of Health. Cross checking of references led to the identification of additional relevant references. The decision to involve or eliminate reviews and data extraction was completed by the authors and any controversy was settled by discussion. The articles included real human data on interventional approaches. Articles related to interventional cardiology were thoroughly searched and later the articles focusing mostly on transradial versus transfemoral approach in these patients were searched. However, the reviews with high possibility of bias or the studies with hazy and confounded data were excluded. To maintain the high standard of review, studies published in all non-famous journals were excluded. The animal studies were also excluded to maintain focus on human heart diseases. We reviewed 220 articles initially and 43 were included based on their relevance to the role of transradial versus transfemoral approach and its pros and cons in interventional cardiology.

\section{Discussion}


Andreas Gruentzig is considered the father of interventional cardiology because he was the first who successfully performed coronary angioplasty in a human patient in September 1977 [13]. The early results of this treatment, despite using only a carefully kitchen built catheter lab were quite good. The patient was angina free after this treatment. The excellent results of this treatment were lead to the rapid acceptance and growing of angioplasty treatment option. A lot of procedures can be performed on the heart by cardiac catheterization. The classical approach is through femoral sheath poking into the femoral artery. The transradial artery may also be used for cannulation due to numerous benefits over transfemoral, like the accessibility of the artery in most patients, fewer chances of hematoma formation even in anticoagulated patients, the patient comfort, because patients are capable of ambulating immediately following the procedure and easily stopping the bleeding by compression.

\section{Transfemoral approach- the classical approach}

The femoral approach technique can be performed repeatedly in the same patient. The femoral artery is easily palpable and allows for easy access. The transfemoral approach is the method of choice in those patients with absent/difficult to palpate radial and brachial pulsations and for those instances, where the transradial approach has been unsuccessful when the large-caliber catheters are used. In 1970s large guide catheters were used in angioplasty which required large lumen arterial access, so transfemoral approach became the main source of arterial access for coronary catheterization and intervention. It has gained universal acceptance because of the extensive usage and the workforce experience and easy access; furthermore, it also enables the use of larger sheaths and other equipment for the evolution of known complications.

Before 2008, the transfemoral approach was considered as the main route of arterial access for cardiac catheterization in the United States. However, transradial cardiac catheterization in the United States is growing with time due to the significant risk of transfemoral associated major and minor vascular complications related to transfemoral approach. The American College of Cardiology defines vascular complications as minor or major. Minor vascular complications were defined as any of the following: hematoma $<10 \mathrm{~cm}$, fistulae, or pseudoaneurysm [14]. However, the major vascular complications were defined as death caused by major vascular bleeding leading to $>3 \mathrm{~g}$ fall in hemoglobin level due to retroperitoneal bleeding or administration of blood transfusions or vascular repair, vessel occlusion, or loss of pulse [15].

The most common femoral approach vascular complications are; the access site bleeding, hematoma, arteriovenous (AV) fistula, retroperitoneal bleeding, and pseudoaneurysm. In the United States, the proportion of transradial percutaneous coronary intervention (PCI) increased gradually, from $1.2 \%$ in 2007 to $16.1 \%$ in 2012 and a total of $6.3 \%$ of total procedures from 2007 to 2012 [11]. The complication for this procedure includes bleeding which may sometimes require transfusion to treat the bleeding complication. However, the many studies appoint strongly towards the -evidence that these post-procedural bleeding especially retroperitoneal bleeding is associated with a bad prognosis and the blood transfusion after the procedure is also associated with poor prognosis [12].

Elderly and obese patients are more prone to the risk of bleeding complications after the transfemoral approach. A retrospective cohort study is performed in 21,103 obese patients (BMI 40) who underwent percutaneous coronary intervention (PCI) and angiography. The study reports that the patients with the transfemoral approach had more chances of bleeding and access side vascular complications as compared to the transradial approach patients who had fewer chances of bleeding complications. The patient morbidity rate had reduced with transradial approach [16]. The pros and cons of transfemoral approach in cardiac catheterization have been summarized in the (Table-1) [1-2-3, 12-13-14-15]. 


\section{Cureus}

\section{Pros}

Availability of trained and experienced doctors in this approach Large artery diameter Procedural complications are known and its prevention is also available Better for patients with extensive peripheral arterial disease (PAD) Long history of successful approach

\section{Cons}

Risk of Bleeding is high Longer hospital stay

A Pseudoaneurysm and Clot formation

Higher procedural cost Femoral artery is the only source of blood to the leg

\section{TABLE 1: Transfemoral approach's pros and cons}

\section{Transradial approach- the modern approach}

Transradial catheterization is currently more popular in Asia and Europe. The transradial approach coronary angiography was reported for the first time in Campeau [2] and subsequently for transradial angiography in 1989 [17] and coronary stenting in 1993 [18]. The percutaneous coronary intervention (PCI) via the transradial (TR) approach has gained increasing popularity due to less bleeding complications. In the 1970's and 80's, many cardiologists were proficient in transradial approach, thus finishing a catheterization only 10 to 15 minutes longer than transfemoral approach. The radial artery is very superficial, making it easy to puncture and bleeding is controlled by compression. Anatomically, there is no major nerves or veins present near the radial artery, thus, minimizing the risk of nerve and vascular injuries. In the past 10 years, the benefits of transradial access have been documented in many studies. Some benefits of the transradial approach include; less bleeding complications, [1-3, 6, 19-20] lower morbidity, early ambulation, associated with lower total hospital costs compared with transfemoral intervention (TFI) approach [5], patient preference and comfort, easy to compress and hemostasis, same day discharge is possible, less chance of developing ischemia due to dual blood supply of hand and easy access for the patient of myocardial infarction (MI) and aortic aneurysm (AA) [21-22].

Vorobcsuk, et al. performed a pool of data collection on the population of 3324 patients in 12 different studies, who underwent percutaneous coronary intervention [PCI] either via transradial or transfemoral approach. They found a 70\% risk reduction in access-site bleeding with the transradial approach. This attainment further converted into the lower incidence of hospital major adverse cardiac events and mortality [23].

Studies have suggested that transradial approach may reduce hospital mortality among patients with STEMI. The study has shown that 294,769 patients undergone PCI for ST-segment elevation myocardial infarction [STEMI] in between 2007 and 2011. Data shows less bleeding complications and lower hospital morbidity and mortality rate by transradial approach [24]. Radial approach is considered better for coronary stenting than femoral in patients with the acute coronary syndrome. Access site bleeding complications are less and shorter hospital stay results in decrease morbidity and mortality [19]. A significant benefit of transradial catheterization is faster, more comfortable recovery. A cohort study included 334 end stage liver failure patients, have shown that transradial approach decreased the risk of bleeding, lower vascular complications and pseudoaneurysm as compared to the classical approach in patients with end-stage liver disease [25].

In some instances, the patients with ST-elevation myocardial infarction [STEMI] may require antithrombotic therapy and have the high risk of bleeding. However, the studies have shown that transradial approach is safe and efficient for coronary angiography in these patients [26]. A study conducted by Sciahbasi AT showed the frequency of bleeding and mortality due to 


\section{Cureus}

transradial approach and has been demonstrated in an extensive study in PCI [27]. Similar observational study on thousand non-ST-segment elevations myocardial infarction [NSTEMI] patients has been demonstrated in transradial treated cases [28].

Greenberg G, et al. performed analysis on 4873 consecutive patients from April 2007 to July 2012 who underwent PCI at a community hospital. He studied a comparison between transradial versus transfemoral approaches in these patients. The study showed that the hospitalization was shorter in the transradial intervention as compared to transfemoral intervention [29]. PCI is still relatively underused in the United States and the reason behind is the immense challenge in various aspects, including slight diameter calcification and fibrosis in senior patients. The small size and the incidence of radial artery spasm create problems in obtaining vascular access. Radial artery occlusion is another major complication of transradial approach, but most of them are asymptomatic. Radial artery occlusion can be reduced by using small diameter catheter, using anticoagulation and applying enough pressure on the radial artery to stop bleeding and by this way we can reduce asymptomatic occlusion significantly [30].

Coronary angiography via transradial approach become very popular worldwide and is becoming more accepted in recent years, based on a reduction in vascular complications and mortality as compared with the transfemoral approach [31-32]. However, these benefits come at the cost of increased procedure time and fluoroscopy dose [33-34]. There is also a concern that transradial approach may delay time to reperfusion if vascular access time is increased or difficult anatomy requiring multiple catheter exchanges. However, because of its realistic and feasible approach, the United States will continue to experience a shift towards a transradial approach. Sooner rather than later, the landscape in the United States will mirror that of Europe and Asia [35-39]. In these days, both patients and staff prefer the transradial approach because of these benefits. As a result of these advantages, transradial approach is popular in worldwide. The pros and cons of transradial approach in cardiac catheterization have been summarized in the (Table-2) [1-2-3, 19-20-21-22-23].

\section{Pros}

Low morbidity and mortality Risk of bleeding complication and hematoma formation are low Low procedural cost Early discharge even the same day Radial artery is not the only source of blood to the hand No nothing by mouth (NPO) restriction soon after the procedure

\section{Cons}

Unavailability many trained and experienced doctors Due to small radial artery diameter, procedure is difficult to perform More time is required as compared to femoral approach Procedural complications such as shunt or fistula Postprocedural severe vascular spasm like (Raynaud's)

\section{TABLE 2: Transradial approach's pros and cons}

In the last decade, transradial and transfemoral approaches in the cardiac catheterization have been largely studied and have been an area of major interest in intervention cardiology [2, 5, $13,25,35,37]$. Though, the data on both approached implies on their efficacy, practicality, and benefits; however, both approaches also have their complications. Through the available data in the scientific literature, the findings from some of the relevant studies showing the role of transradial and transfemoral approaches in the cardiac catheterization have been summarized in the (Table - 3) [16, 19, 24-25, 40-41-42-43]. 


\section{Cureus}

\begin{tabular}{|c|c|c|c|c|}
\hline $\begin{array}{l}\text { Author and } \\
\text { the year of } \\
\text { publication }\end{array}$ & $\begin{array}{l}\text { Study } \\
\text { design }\end{array}$ & Sample size & Diagnostic criteria & Study findings \\
\hline
\end{tabular}

Kedev S, et

al. 2014 [3]

Roussanov

$\mathrm{O}$, et al.

2007 [5]

Jang JS, et al. 2012

[10]

Tewari S, et

al. $2013 \quad$ Clinical trial
[15]

Hibbert B,

et al. 2012 Cohort study

[16]

Mann T, et al. 1998
Clinical trial

Cohort study

Systematic review and metaanalysis

\section{STEMI patients \\ $(\mathrm{n}=1808)$ who underwent $\mathrm{PCl}$ using transradial approach} $(n=1162)$ and transfemoral approach $(n=646)$ from October 2007 to December 2010 were enrolled

from October 2004 to May 2006, a total of 181 patients who underwent diagnostic cardiac

catheterization at Salem Veterans Affairs Medical Center

Twenty-one studies involving 8,534 patients were identified

26,238 patients, who underwent $\mathrm{PCl}$ procedures $55.65 \%$ and $44.35 \%$ procedures were done through TF and TR approach

Out of 21,103 patients procedures, 564 were performed in unique EO patients: 203 via the transradial approach and 361 via the transfemoral approach
Comparison of short- and long-term outcomes of transradial approach (TRA) versus transfemoral approach (TFA) for primary percutaneous coronary intervention (PPCl)

Cost comparisons have been made between the radial and femoral approaches to diagnostic cardiac catheterization

TR approach is associated with lower incidence of complications in vascular access site and improved clinical outcomes compared with TF approach in the setting of STEMI

Comparison of transradial and transfemoral artery approach for percutaneous coronary procedures

\section{Transradial versus} transfemoral access for coronary angiography and $\mathrm{PCl}$ in patients with a body mass index $\geq 40$

To compare the transradial approach with the transfemoral approach for
Complete transition from femoral access to a radial access is safe and effective for STEMI patients undergoing $\mathrm{PPCl}$, with a favorable effect on short- and long-term outcomes

The radial artery approach to diagnostic cardiac catheterization is clearly more cost effective than the femoral approach.

$\mathrm{TR}-\mathrm{PCl}$ reduces the risk of significant periprocedural bleeding and improve clinical outcomes in patients with STEMI

Number of TR approaches have increased significantly with reduced complication rates and comparable success rate to TF approach, with the additional benefits in terms of patient comfort, preference and reduced cost of procedure

TF access for coronary angiography and $\mathrm{PCl}$ was associated with more access site and bleeding complications compared with a TR approach

Coronary stenting from the transradial approach is 


\section{Cureus}

clinical trial

Baklanov

DV, et al.

Clinical trial

2013 [24]

Feng $\mathrm{K}$, et

al. 2014

[25]

Retrospective cohort study

Jolly SS, et al. 2009 [31]

Metaanalysis

Neill J, et

al. 2010

Clinical trial

[34]

Kiemeneij

$F$, et al.

Clinical trial

1997 [39]

Kołtowski L, et al. 2014

[40] coronary stenting in patients

with acute coronary

syndromes

294,769 patients undergoing $\mathrm{PCl}$ for

STEMI at 1,204

hospitals in the Cath

$\mathrm{PCl}$ Registry between

2007 and 2011

334 end-stage liver

disease (ESLD)

patients

Randomized trials

comparing radial

versus femoral

access coronary

angiography from

2005 to April 2008

were included

Femoral access

cases $(n=848,412$

diagnostic, 436

percutaneous

coronary interventions

[PCls]) and radial

access cases $(\mathrm{n}=$

965, 459 diagnostic,

$506 \mathrm{PCls}$ ) were

assessed

A randomized comparison between transradial, trans-

brachial and

transfemoral PTCA

with $6 \mathrm{~F}$ guiding

catheters was

performed in 900

patients

Transfemoral and transradial cardiac catheterizations in ESLD patients

The objective of this metaanalysis was to determine if radial access reduces major bleeding and as a result can reduce death and ischemic events compared to femoral access

Fluoroscopy time (FT) and dose-area product (DAP) were recorded for all radial access and femoral access procedures during default femoral access, transition phase (femoral access and early radial access), and default radial access

Comparison of procedural and clinical outcomes of percutaneous transluminal coronary angioplasty (PTCA) performed with $6 \mathrm{~F}$ guiding catheters introduced through the radial, brachial or femoral arteries

Cost effectiveness and complication of Minor bleedings in transradial versus transfemoral access percutaneous coronary interventions for STEMI efficacious in patients with acute coronary syndromes

The transradial approach was associated with lower bleeding rate and reduced in-hospital mortality

TR group had a significantly lower rate of pseudoaneurysms and bleeding complications

Radial access reduced major bleeding and there was a corresponding trend for reduction in ischemic events compared to femoral access. Large randomized trials are needed to confirm the benefit of radial access on death and ischemic events

Transition from femoral access to radial access for diagnostics and $\mathrm{PCl}$ increased FT. DAP increased for diagnostic radial access but not $\mathrm{PCl}$ compared with femoral access. FTs for radial access diagnostic cases decreased with experience

With experience, procedural and clinical outcomes of PTCA were similar for the three subgroups, but access failure is more common during TR - PTCA. Major access site complications were more frequently encountered after trans-brachial and TF - PTCA

The indirect costs were lower in the radial group. Transfemoral approach had a higher risk of access-related bleedings than transradial approach

Radial procedures were 


\section{Cureus}

Singh G, et al. 2016

[41]

Retrospective study

163 radial and 180

femoral access

Iqa $\mathrm{A}$, et al.

2014 [42]

Clinical trial

$507 \mathrm{Ml}$ patients

Brueck M, et al. 2009

[43]
Differences in the procedural variables between transradial and transfemoral access for coronary angiography, with cardiology fellows as the primary operators

To compare the clinical results of transradial and transfemoral in Ml patients who had cardiogenic shock and underwent $\mathrm{PCl}$

TR approach comparison with TF approach in the standard population of patients undergoing coronary catheterization associated with more radiation and prolonged procedural time. Although total procedural time decreased for radial cases with the level of training, total radiation dose did not decrease

TR approach is associated with fewer major bleeding and vascular complications than TF approach especially in complicated cardiogenic shock patients

The rate of major vascular complications was negligible using the TR approach

\section{TABLE 3: The role of transradial and transfemoral approaches in the cardiac catheterization in relevant studies}

\section{Conclusions}

We conclude that although the transfemoral is being an old traditional approach, the transradial is the more modern approach. The most imperative question is that, are both of these approaches useful?. The evidence implies that both of these methods have been useful and fruitfully used in the past and the present. However, like any procedure, these two methods have their complications as well several studies suggest that the modern approach overweights in benefits with the comparison to the classical approach.

Complete transition from femoral approach to a radial approach is safe and successful in many cardiovascular procedures. The findings of the recent studies have shown that the transradial approach in cardiac catheterization is safe, cost-effective, and feasible with similar results to those of the transfemoral approach. However, duration and radiation exposure are higher in the transradial access. As the time passes, more research is being conducted and obviously more studies will be published in the future that will be able to target to find how to lessen the duration and the radiation exposure in transradial approach. Thus, the future studies will broaden our knowledge about the further possible benefits and complications of both the approaches.

\section{Additional Information \\ Disclosures}

Conflicts of interest: In compliance with the ICMJE uniform disclosure form, all authors declare the following: Payment/services info: All authors have declared that no financial support was received from any organization for the submitted work. Financial relationships: All authors have declared that they have no financial relationships at present or within the previous three years with any organizations that might have an interest in the submitted work. 
Other relationships: All authors have declared that there are no other relationships or activities that could appear to have influenced the submitted work.

\section{Acknowledgements}

We would like to thank Dr Hassan Tohid for his assistance, helpful discussion and reading the manuscript

\section{References}

1. Barton M, Gruntzig J, Husmann M, et al.: Balloon angioplasty - The legacy of Andreas Grüntzig, M.D. (1939-1985). Front Cardiovasc Med. 2014, 1:15. 10.3389/fcvm.2014.00015

2. Bourassa MG: The history of cardiac catheterization. Can J Cardiol. 2005, 21:1011-1014.

3. Kedev S, Kalpak O, Dharma S, et al.: Complete transitioning to the radial approach for primary percutaneous coronary intervention: a real-world single-center registry of 1808 consecutive patients with acute ST-elevation myocardial infarction. J Invasive Cardiol. 2014, 26:475-482.

4. Sinha SK, Mishra V, Afdaali N, et al.: Coronary angiography safety between transradial and transfemoral access. Cardiol Res Pract. 2016, 2016:1-7. 10.1155/2016/4013843

5. Roussanov O, Wilson SJ, Henley K, et al.: Cost-effectiveness of the radial versus femoral artery approach to diagnostic cardiac catheterization. J Invasive Cardiol. 2007, 19:349-353.

6. Pasley TF, Khan A, Yen LY, et al.: Left radial versus femoral access for coronary angiography in post-coronary artery bypass graft surgery patients. J Invasive Cardiol. 2016, 28:81-84.

7. Williams PD, Palmer S, Judkins C, et al.: Right and left heart catheterization via an antecubital fossa vein and the radial artery--a prospective study. J Invasive Cardiol. 2014, 26:669-673.

8. Slawin J, Kubler P, Szczepanski A, et al.: Radial artery occlusion after percutaneous coronary interventions - an underestimated issue. Postep Kardiol Inter. 2013, 9:353-361. 10.5114/pwki.2013.38865

9. Aamir S, Mohammed S, Sudhir R: Transradial approach for coronary procedures in the elderly population. J Geriatr Cardiol. 2016, 13:798-806. 10.11909/j.issn.1671-5411.2016.09.002

10. Jang JS, Jin HY, Seo JS, et al.: The transradial versus the transfemoral approach for primary percutaneous coronary intervention in patients with acute myocardial infarction: a systematic review and meta-analysis. EAPCI. 2012, 8:501-510. 10.4244/eijv8i4a78

11. Fa'ak F, Shabaneh B, Younis G: Direct measurement of left atrial pressure during routine transradial catheterization. Tex Heart Inst. 2016, 43:503-506. 10.14503/thij-15-5508

12. Rao SV, Eikelboom JA, Granger CB, et al.: Bleeding and blood transfusion issues in patients with non-ST-segment elevation acute coronary syndromes. Eur Heart J. 2007, 28:1193-1204. 10.1093/eurheartj/ehm019

13. Meier B: The first patient to undergo coronary angioplasty-23-year follow-up. N Engl J Med. 2001, 344:144-145. 10.1056/nejm200101113440217

14. Applegate RJ, Grabarczyk MA, Little WC, et al.: Vascular closure devices in patients treated with anticoagulation and IIb/IIIa receptor inhibitors during percutaneous revascularization. J Am Coll Cardiol. 2002, 40:78-83.

15. Tewari S, Sharma N, Kapoor A, et al.: Comparison of transradial and transfemoral artery approach for percutaneous coronary angiography and angioplasty: a retrospective seven-year experience from a north Indian center. Indian Heart J. 2013, 65:378-387.

10.1016/j.ihj.2013.06.020

16. Hibbert B, Simard T, Wilson KR, et al.: Transradial versus transfemoral artery approach for coronary angiography and percutaneous coronary intervention in the extremely obese. JACC Cardiovasc Interv. 2012, 5:819-826. 10.1016/j.jcin.2012.04.009

17. Campeau L: Percutaneous radial artery approach for coronary angiography. Cathet Cardiovasc Diagn. 1989, 16:3-7.

18. Kiemeneij F, Laarman GJ: Percutaneous transradial artery approach for coronary stent implantation. Catheter Cardiovasc Interv . 1993, 30:173-178. 10.1002/ccd.1810300220

19. Mann T, Cubeddu G, Bowen J, et al.: Stenting in acute coronary syndromes: a comparison of radial versus femoral access sites. J Am Coll Cardiol. 1998, 32:572-576. 10.1016/S07351097(98)00288-5 
20. De Maria GL, Burzotta F, Trani C et. al: Trends and outcomes of radial approach in left-main bifurcation percutaneous coronary intervention in the drug-eluting stent era: A two-center registry. J Invasive Cardiol. 2015, 27:125-136.

21. Cooper CJ, El-Shiekh RA, Cohen DJ, et al.: Effect of transradial access on quality of life and cost of cardiac catheterization: A randomized comparison. Am Heart J. 1999, 138:430-436. 10.1016/S0002-8703(99)70143-2

22. Mann JT, Cubeddu MG, Schneider JE, et al.: Right radial access for PTCA: a prospective study demonstrates reduced complications and hospital charges. J Invasive Cardiol. 8; 1996. Suppl:40-44.

23. Komócsi A, Aradi D, Kehl, et al.: Meta-analysis of randomized trials on access site selection for percutaneous coronary intervention in ST-segment elevation myocardial infarction. Arch Med Sci. 2014, 10:203-212. 10.5114/aoms.2014.42570

24. Baklanov DV, Kaltenbach LA, Marso SP, et al.: The prevalence and outcomes of transradial percutaneous coronary intervention for ST-segment elevation myocardial infarction: Analysis from the National Cardiovascular Data Registry (2007 to 2011). J Am Coll Cardiol. 2013, 61:420-426. 10.1016/j.jacc.2012.10.032

25. Feng K, Gupta V, Terrazas E, et al.: Trans-radial versus trans-femoral access in patients with end-stage liver disease undergoing cardiac catheterization. Am J Cardiovasc Dis. 2014, 4:133139.

26. Jolly SS, Amlani S, Hamon M, et al.: Radial versus femoral access for coronary angiography or intervention and the impact on major bleeding and ischemic events: A systematic review and meta-analysis of randomized trials. Am Heart J. 2009, 157:132-140. 10.1016/j.ahj.2008.08.023

27. Sciahbasi A, Pristipino C, Ambrosio G, et al.: Arterial access-site-related outcomes of patients undergoing invasive coronary procedures for acute coronary syndromes (from the Comparison of early invasive and conservative treatment in patients with non-ST-elevation acute coronary syndromes [presto-acs] vascular substudy). Am J Cardiol. 2009, 103:796-800. 10.1016/j.amjcard.2008.11.049

28. Chase AJ, Fretz EB, Warburton WP, et al.: Association of the arterial access site at angioplasty with transfusion and mortality: the M.O.R.T.A.L study (Mortality benefit of reduced transfusion after percutaneous coronary intervention via the arm or leg). Interv Cardiol. 2008, 94:1019-1025. 10.1136/hrt.2007.136390

29. Greenberg G, Bental T, Lev EI, et al.: A comparative matched analysis of clinical outcomes between transradial versus transfemoral percutaneous coronary intervention. Isr Med Assoc J. 2015, 17:360-364.

30. Pancholy S, Coppola J, Patel T, et al.: Prevention of radial artery occlusion-patent hemostasis evaluation trial (PROPHET study): A randomized comparison of traditional versus patency documented hemostasis after transradial catheterization.. Catheter Cardiovasc Interv. 2008, 72:335-340. 10.1002/ccd.21639

31. Jolly SS, Yusuf S, Cairns J, et al.: Radial versus femoral access for coronary angiography and intervention in patients with acute coronary syndromes (RIVAL): A randomized, parallel group, multicentre trial. Lancet. London; 2011. 377:1409-1420. 10.1016/s01406736(11)60404-2

32. Romagnoli E, Biondi-Zoccai G, Sciahbasi A, et al.: Radial versus femoral randomized investigation in ST-segment elevation acute coronary syndrome: the RIFLE-STEACS (Radial Versus Femoral Randomized Investigation in ST-Elevation Acute Coronary Syndrome) study. J Am Coll Cardiol. 2012, 60:2481-2489. 10.1016/j.jacc.2012.06.017

33. Michael TT, Alomar M, Papayannis A, et al.: A randomized comparison of the transradial and transfemoral approaches for coronary artery bypass graft angiography and intervention: the RADIAL-CABG Trial (RADIAL versus femoral access for coronary artery bypass graft angiography and intervention). JACC Cardiovasc Interv. 2013, 6:1138-1144. 10.1016/j.jcin.2013.08.004

34. Neill J, Douglas H, Richardson G, et al.: Comparison of radiation dose and the effect of operator experience in femoral and radial arterial access for coronary procedures. Am J Cardiol. 2010, 106:936-940. 10.1016/j.amjcard.2010.06.002

35. Schneider JE, Mann T, Cubeddu MG, et al.: Transradial coronary stenting: A United States experience. J Invasive Cardiol. 1997, 9:569-574.

36. Saito S, Miyake S, Hosokawa G, et al.: Transradial coronary intervention in Japanese patients. Catheter Cardiovasc Interv. 1999, 46:37-41. 10.1002/(SICI)1522-726X(199901)46:1<37::AID- 


\section{Cureus}

CCD10>3.0.CO;2-Y

37. Wu CJ, Lo PH, Chang KC, et al.: Transradial coronary angiography and angioplasty in Chinese patients. Catheter Cardiovasc Interv. 1997, 40:159-163. 10.1002/(SICI)1097-

0304(199702)40:2<159::AID-CCD8>3.0.CO;2-A

38. Chodor P, Kurek T, Kowalczuk A, et. al: Radial vs femoral approach with StarClose clip placement for primary percutaneous coronary intervention in patients with ST-elevation myocardial infarction. RADIAMI II: a prospective, randomized, single-center trial.. Kardiol Pol. R.A.D.I.A.M.I. (ed): 2011. 69:763-771.

39. Kiemeneij F, Laarman GJ, Odekerken D, et. al: A randomized comparison of percutaneous transluminal coronary angioplasty by the radial, brachial and femoral approaches: the access study. J Am Coll Cardiol. 1997, 29:1269-1275.

40. Koltowski L, Filipiak KJ, Tomaniak M, et al.: A prospective randomized comparison of minor bleedings in transradial vs. transfemoral access percutaneous coronary interventions for STEMI: a new FEMORAL bleeding classification. Kardiol Pol. 2014, 72:790-797.

10.5603/KP.a2014.0109

41. Singh G, Campos E, Kavinsky CJ, et. al: Comparative analysis of radial versus femoral diagnostic cardiac catheterization procedures in a cardiology training program. JACC Cardiovasc Interv. 2016, 28:254-257.

42. Iga A, Wagatsuma K, Yamazaki J, et al.: Transradial versus transfemoral coronary intervention for acute myocardial infarction complicated by cardiogenic shock: is transradial coronary intervention suitable for emergency PCI in high-risk acute myocardial infarction?. J Invasive Cardiol. 2014, 26:196-202.

43. Brueck M, Bandorski D, Kramer W, et al.: A randomized comparison of transradial versus transfemoral approach for coronary angiography and angioplasty. JACC Cardiovasc Interv. 2009, 2:1047-1054. 10.1016/j.jcin.2009.07.016 